\title{
Netnografia da Educação Física na reforma do ensino médio brasileiro: práticas discursivas nas redes sociais youtube, instagram, facebook e twitter
}

\section{RESUMO}

Este estudo organiza-se em torno das seguintes questões: quais são as práticas discursivas empreendidas, no ciberespaço, sobre as possíveis ressonâncias da reforma do ensino médio sobre o componente curricular Educação Física? Almejase, identificar e analisar os modos como os sujeitos do/no lugar online evocam o lugar da Educação Física no contexto dessa reforma. Desse modo, realizou-se uma netnografia das redes sociais Facebook.com, Instagram.com, Twitter.com e Youtube.com, utilizando como fonte as narrativas veiculadas por atores sociais que discutiram e/ou se manifestaram sobre a MP $\mathrm{n}^{\mathbf{0}} 746$ nesses lugares online. Os resultados sinalizam para obrigatoriedade posta em xeque da Educação Física no ensino médio, cujas narrativas apresentadas se organizam desde as frustações com conteúdos sobrepostos até a dificuldade de entendimento do lugar e sentido das aprendizagens desse componente curricular nessa etapa da escolarização.

PALAVRAS-CHAVE: Educação física; Reforma; Ensino médio; Ciberespaço
Murilo Eduardo dos Santos Nazário

Doutor em Educação Física - UFES Universidade Vila Velha, Curso de Educação Física, Vila Velha, Espírito Santo, Brasil murilo.nazario@uvv.br

(ㄱ) https://orcid.org/0000-0001-8271-2260

Wagner dos Santos

Doutor em Educação - UFES Universidade Federal Espírito Santo - UFES, Programa de Pós-Graduação em Educação e Programa de Pós-Graduação em Educação Física

Vitória, Espírito Santo, Brasil wagnercefd@gmail.com

http://orcid.org/0000-0002-9216-7291

Amarílio Ferreira Neto

Doutor em Educação - UNIMEP Universidade Federal do Espírito SantoUFES, Programa de Pós-Graduação em Educação Física

Vitória, Espírito SantoBrasil amariliovix@gmail.com http://orcid.org/0000-0002-3624-4352 
Netnography of Physical Education in the reform of brazilian high school: discursive practices on social networks youtube, instagram, facebook and twitter

\begin{abstract}
This study is organized around the following questions: what are the discursive practices undertaken in cyberspace about the possible resonances of the high school reform on the curriculum component Physical Education? It is also hoped to identify and analyze the ways in which the subjects of/in the online place evoke the place of Physical Education in the context of this reform. In this way, a netnography was realized in the social networks Facebook.com, Instagram.com, Twitter.com and Youtube.com, using as a source the narratives presented by social actors who discussed and/or manifested themselves on MP $n^{\circ} 746$ in these places online. The results point to the compulsory challenge of physical education in high school, whose narratives are organized from the frustrations with overlapping contents to the difficulty of understanding the place and the meaning of the learning of this curricular component in this stage of schooling.
\end{abstract}

KEYWORDS: Physical education; Reform; High school; Cyberspace

Netnografía de la Educación Física en la reforma de la escuela secundaria brasileña: prácticas discursivas en las redes sociales youtube, instagram, facebook y twitter

\title{
RESUMEN
}

Este estudio se organiza alrededor de las siguientes preguntas: ¿cuáles son las prácticas discursivas emprendidas en el ciberespacio sobre las posibles resonancias de la reforma de la escuela secundaria en el componente curricular de Educación Física? También tiene como objetivo identificar y analizar las formas en que los sujetos del/en lugar en línea evocan el lugar de la educación física en el contexto de esta reforma. Así, se realizó una netnografía de las redes sociales Facebook.com, Instagram.com, Twitter.com y Youtube.com, utilizando como fuente las narraciones transmitidas por actores sociales que discutieron y/o manifestaron sobre el MP No. 746 en estos lugares en línea. Los resultados apuntan al cuestionamiento obligatorio de la educación física en la escuela secundaria, cuyas narraciones presentadas están organizadas desde frustraciones con contenidos superpuestos hasta la dificultad de comprender el lugar y el significado del aprendizaje de este componente curricular en esta etapa de la escuela.

PALABRAS-CLAVE: Educación física; Enseñanza secundaria; Cyberespacio 


\section{INTRODUÇÃO}

Em 22 de setembro de 2016, o então ministro da Educação envia ao Congresso Nacional, por meio da Medida Provisória n. ${ }^{\circ}$ 746, um plano de reforma do ensino médio brasileiro, cuja estrutura central girava em torno da composição curricular dessa etapa da educação básica. Nessa versão encaminhada, os componentes curriculares seriam reorganizados e distribuídos em itinerários formativos, a saber: linguagens e suas tecnologias, ciências da natureza e suas tecnologias, matemática e suas tecnologias, ciências humanas e sociais aplicadas e formação técnica e profissional. Com isso, a partir de um ano e meio de ensino médio cursado, os alunos escolheriam um desses itinerários para concluir esse percurso de formação.

Todavia, o texto final, que altera a LDB n. ${ }^{0}$ 9.394/1996 e colabora na subtração das Diretrizes Curriculares Nacionais, manteve a Educação Física, Artes, Sociologia e Filosofia como componentes curriculares obrigatórios, mas deixou sem orientação as principais questões no que se refere à estrutura, oferta e compartilhamento desses componentes, disponibilizados em um dos cinco itinerários formativos, os elementos específicos ficarão a cargo das definições que serão estabelecidas com a implantação da Base Nacional Comum Curricular (BNCC). ${ }^{1}$

Essas alterações desencadearam uma série de manifestações, quase instantâneas, de entidades, tais como: a Associação Nacional de Pós-Graduação e Pesquisa em Educação (Anped) em 23 de setembro; a Associação Nacional de História (Anpuh) em 26 de setembro; e o Conselho Nacional de Educação Física (Confef) em 28 de setembro.

Paralelamente, as principais mídias sociais brasileiras "quebraram a internet", ${ }^{2}$ com diferentes postagens que se referiam a essas alterações, seja por textos curtos via $\#^{3}$ vinculados no www.twitter.com.br, seja via imagem, como no www.instagram.com, vídeos postados no www.youtube.br, seja por meio da junção dos três signos: textos, vídeos e imagens, como $w w w$.facebook.com. Elementos que chamam a atenção pela representação que essas mídias possuem no contexto social brasileiro. Um dos dados dessa condição refere-se ao número de usuários que elas possuem no Brasil: o Facebook tem 129 milhões de usuários; o Instagram, 35 milhões; o

\footnotetext{
${ }^{1}$ A última versão entregue pelo MEC, em abril de 2018, apresentou maiores estruturas em relação aos direcionamentos para área de Matemática e Linguagens, em específico o componente curricular Língua Portuguesa. Com isso, as demais áreas e seus respectivos componentes curriculares ainda terão de esperar as elaborações dos currículos das demais instâncias de educação.

${ }^{2}$ Gíria utilizada pelos internautas para descrever uma movimentação interna mediante compartilhamentos, curtidas e comentários intensos na internet sobre um mesmo assunto.

${ }^{3}$ Hashtag é um composto de palavras-chave, ou de uma única palavra, que é precedido pelo símbolo cerquilha (\#). Tags significam etiquetas e referem-se a palavras relevantes que, associadas ao símbolo \#, se tornam hashtags, que são amplamente utilizadas nas redes sociais, em especial no Twitter, onde a adesão delas as tornou muito popular. Esse tipo de marcação utilizada nas redes sociais e em outros meios serve para associar uma informação a um tópico ou discussão. Geralmente essas hashtags se tornam links indexáveis pelos mecanismos de busca (CANALTECH, 2016).
} 
Twitter, 33,3 milhões; e o Youtube, 82 milhões (RIBEIRO, 2019). Esses números fazem dessas mídias extensões de/e cotidianos próprios, inclusive para discutir a reforma do ensino médio, constituindo-se como lugares emergentes de difusão e compartilhamento de informações, ideias, perspectivas e possíveis campos de pesquisa, que mantêm a discussão atualizada e reatualizada em torno dessas mudanças, contando a história em tempo real por intermédio de seus atores.

Elas forneceram visibilidade a questionamentos e reflexões dos praticantes do cotidiano escolar, uma vez que, entre os diferentes usos e consumos (CERTEAU, 2002), as mídias podem ser consideradas ferramentas de difusão e compartilhamento de ideias, opiniões, fatos, dados, críticas, frustrações e perspectivas. Ainda evocam uma dupla compreensão do espaço e tempo cotidiano: a primeira apresenta-se como extensão do lugar praticado e a segunda como lugar próprio a ser praticado. Ou seja, elas recebem componentes narrativos cujos valores são de sintaxes espaciais, as quais indicam um processo configurativo estabelecido por conexões e relações sociais, expressas por trocas constantes, migrações, deslocamentos e trânsitos de um espaço ou de um lugar para outro.

A internet constitui-se como lugar que se estende em um movimento de interconexão, não existindo mais a relação real e virtual, mas apenas um lugar. Para Levy (1999, p. 47), “[...] o virtual na ótica filosófica é toda entidade desterritorializada capaz de gerar diversas manifestações concretas em diferentes momentos e locais determinados, sem, contudo, estar ela mesma presa a um lugar ou tempo em particular".

No caso das mídias sociais como experiências desse virtual, elas podem ser também compreendidas como interfaces, que possibilitam a interação por textos, sons, imagens, vídeos e mesmo a leitura, que permitem a máxima ligação do mundo ordinário com o mundo virtual (LEVY, 1999). Já Poissant (2009) considera que uma das estruturas fundamentais das interfaces é possibilitar a transfiguração do sujeito espectador para ator, conectando homens e máquinas. Para isso, a autora usa o termo artesmídias, que transforma as interfaces em tipos condutores e modificadores dos fazeres cotidianos, com menções a uma possível estética artística, em que pessoas podem ser escritores, colunistas, artistas, pintores, cineastas e músicos.

Desse modo, neste estudo buscam-se respostas para as seguintes questões: quais são as práticas discursivas empreendidas, no ciberespaço, sobre as possíveis ressonâncias da reforma do ensino médio sobre o componente curricular Educação Física? Almeja-se ainda, identificar e analisar os modos como os sujeitos do/no lugar online evocam o lugar da Educação Física no contexto dessa reforma. 


\section{MÉTODOS}

O espaço virtual, ou ciberespaço, tem-se constituído como lugar de possibilidades ímpares para a realização de novas etnografias, seja investigando grupos específicos que participam de blogs, seja passando pelas redes sociais até alcançar sites específicos sobre uma determinada temática.

Para Aguiar (2007, p. 4), “[...] a etnografia digital ou online, compreende a observação dos sujeitos em seu processo de construção de percepções e comportamentos na relação social em rede [...]”. Essa vertente metodológica começou a ser explorada desde o surgimento de comunidades virtuais, no fim dos anos 1980.

A transposição dessa metodologia para o estudo de práticas comunicacionais mediadas por computador recebe o nome de Netnografia, ou etnografia virtual e sua adoção é validada no campo da comunicação pelo fato de que muitos objetos de estudo localizam-se no ciberespaço (MONTARDO; ROCHA, 2005, p. 1).

Desse modo, realizou-se uma netnografia nas interfaces das redes sociais Facebook.com, Instagram.com, Twitter.com e Youtube.com, utilizando como fonte as narrativas (textuais, imagéticas ou audiovisuais) veiculadas por atores sociais que discutiram e/ou se manifestaram sobre a MP $n^{\circ} 746$ nesses lugares online. Diante das particularidades que envolviam cada uma das plataformas na produção de suas materialidades textuais, foi necessário estabelecer alguns critérios de exclusão e seleção: o primeiro deles refere-se à clareza em torno da formulação da questão de pesquisa, pois seria inviável analisar tudo que envolvia o ensino médio e a educação física, que foi publicado ao longo do tempo. Desse modo, optou-se por assumir como objeto de estudo, a reforma dessa etapa de ensino, pois a mesma apresentaria uma marcação histórica significativa e um volume menor de dados, mas também sinalizaria outras informações sobre essa fase da escolarização. $\mathrm{O}$ segundo elemento diz respeito à abrangência temporal de incursão do pesquisador. Para tanto, consideramos apenas as postagens realizadas desde 22 de setembro de 2016, data de emissão da MP/746, até 16 de Fevereiro de 2017, data do sancionamento da Lei 13.415. E o terceiro elemento relaciona-se ao entrée cultural (KOZINETS, 2014), para o qual foi criada uma conta em cada uma das redes sociais selecionadas.

Sequencialmente utilizamos formas de buscas específicas para cada rede social, como por exemplo, empregou-se os descritores: "mpdoensinomedio" e "reformaensinomedio" no Youtube e Faceboook; e o uso de hashtag (\#) antes dos descritores \#ensinomedio, \#reformaensinomedio no 
Twitter e Instagram. Essa ação possibilitou filtrar as narrativas dos sujeitos por meio de elementos textuais, imagéticos e audiovisuais.

Em seguida, mediante as recomendações de Kozinets (2014), foi realizado o processo de observação, entre os dias 23 de setembro de 2016 e 16 de fevereiro de 2017, optando pelo anonimato, dadas as particularidades de análise da pesquisa e o volume extenso de resultados já produzidos até os dias das imersões analíticas. Como as discussões e participações dos membros giravam em torno da medida provisória, optamos por não formular entrevistas ou mesmo temas geradores de discussão por meio de novas postagens, preferimos analisar o material já produzido, denominados dados arquivais. Assim, manteve-se acompanhamento diário e extensivo de quase 5 horas observando as discussões e interações dos participantes nas redes sociais analisadas. Vale ressaltar que todas as páginas, a partir da criação de login, não precisavam de pré-requisitos cadastrais ou autorização para acesso as informações, comentários e postagens. Com isso, analisava-se, de acordo com cada uma das redes sociais, interações como essas da figura 1:

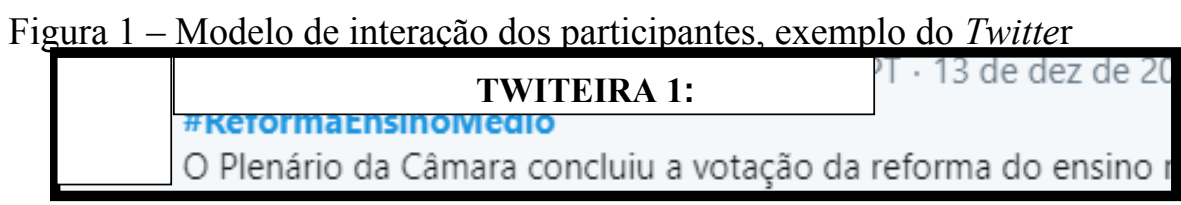

Fonte: Extraída do Twitter.

Na rede social Twitter, as pessoas podem interagir produzindo um twit inicial, que por sua vez possibilita a interação de outros usuários, seja curtindo, conforme figura do coração, retweetando com base na figura de centro, ou podem participar tecendo comentários conforme figura do balão. Em cada uma das plataformas analisadas há interfaces próprias que facilitam esse tipo de comunicação, mas mantém essa inter-relação entre postagem inicial e demais participações.

A segunda fase das pesquisas netnográficas é dedicada às análises e interpretações interativas do material coletado. Para Kozinets (2014), o pesquisador deve esforçar-se para compreender as participações dos membros em articulação com um contexto de discussão. Outro elemento importante que é considerado nas etnografias refere-se à fidedignidade de comportamentos e ações do pesquisado diante do pesquisador, condição que não ocorreu, pois as fontes foram produzidas não por indução do pesquisador, e sim pelas representações e interesses dos participantes dessas mídias sociais.

A partir das especificidades dispostas nas interfaces interativas de cada rede social iniciou-se o processo de leitura e captura integral das narrativas produzidas. Para tanto, em cada uma das páginas analisadas, convertíamos o conteúdo textual em Portable Document Format (PDF), para otimizar o processo de análise. 
Ação que forneceu o seguinte quantitativo por página: Instagram, com \#reformaensinomedio deu origem a 50 páginas com uma postagem cada uma; Facebook, com a \#reformadoensinomédio gerou 15 páginas com 3 a 4 postagens por página, já com \#reformaensinomédio foram produzidas 28 páginas com 3 a 4 postagens; Twitter com a \#mpensinomédio 5 páginas com 7 a 8 postagens por página, com a \#reformaensinomédio 4 páginas com 7 a 8 postagens por página. Em relação ao Youtube, procedeu-se de modo diferente, inicialmente selecionou-se os cinco vídeos com maior número de visualizações e depois de analisados, foram extraídos de cada um os comentários produzidos, fornecendo cerca de 20 páginas com 10 a 12 postagens por vídeo.

Kozinets (2010) recomenda que, diante do volume extenso do material textual coletado, o pesquisador faça uso de softwares de análise qualitativa para reconhecimento e organização semântica. Nessa perspectiva, utilizou-se o Iramuteq $R$, sendo inserido, na interface do software, todo o material coletado, procedimento que produziu uma Nuvem de Palavras ${ }^{4}$ e um Grafo de Similitude ${ }^{5}$ compostas pelos elementos textuais de maior recorrência nas plataformas pesquisadas.

\section{ANÁLISE E DISCUSSÃO DOS RESULTADOS}

Para ampliar o procedimento de análise e impedir um segundo movimento de silenciamento daqueles que não foram ouvidos no cerne de composição e estruturação dessa medida provisória, ou seja, os atores do cotidiano escolar, professores e alunos, principalmente, foram extraídos fragmentos textuais completos de suas participações nas discussões, comentários e participações nas mídias, com o intuito de situar as palavras produzidas pelo software, conforme figura 2, no contexto das narrativas integrais desenvolvidas pelos participantes. Como critério de seleção, optou-se por aquelas que possuíam maior número de comentários ou curtidas, que geralmente se situavam nas primeiras páginas das plataformas.

\footnotetext{
${ }^{4}$ Análise léxica que ocorre a partir do agrupamento e organização das palavras em função da sua frequência (CAMARGO; JUSTO, 2013).

${ }^{5}$ É um tipo de análise que baseia-se na teoria dos grafo que possibilita a identificação das coocorrências entre palavras e suas possíveis conexões (CAMARGO; JUSTO, 2013).
} 
Figura 2 - Nuvem de palavras a partir da recorrência por vocábulo do Iramuteq $R$

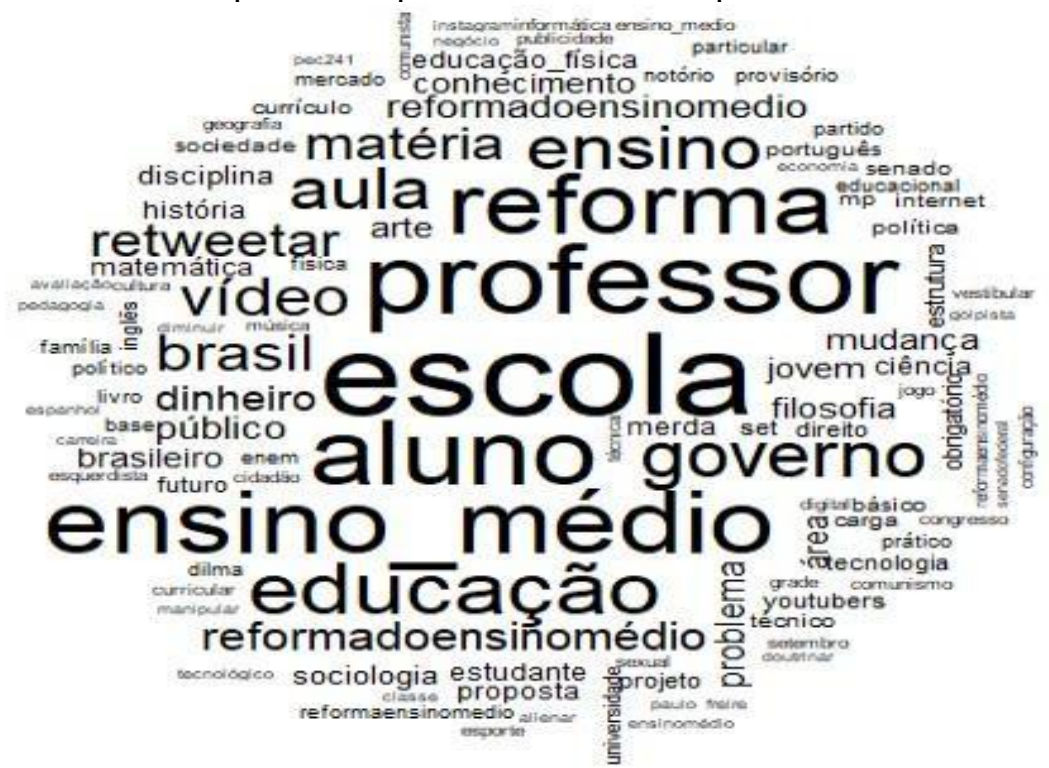

Fonte: Elaborada pelo autor.

Segundo Kozinets (2010, 2014), faz-se significativo articular as ações dos sujeitos em um determinado contexto. Nessa perspectiva foi realizado o procedimento de extração dos vocábulos produzidos pela nuvem de palavras. A grafia textual presente nos vocábulos assume mais sentido quando é articulada com seu intertexto. Para tanto, elaborou-se o grafo de similitude, conforme o IramuteqR, representado pela Figura 3.

Figura 3 - Grafo de similitude da relação entre os vocábulos e o contexto narrativo

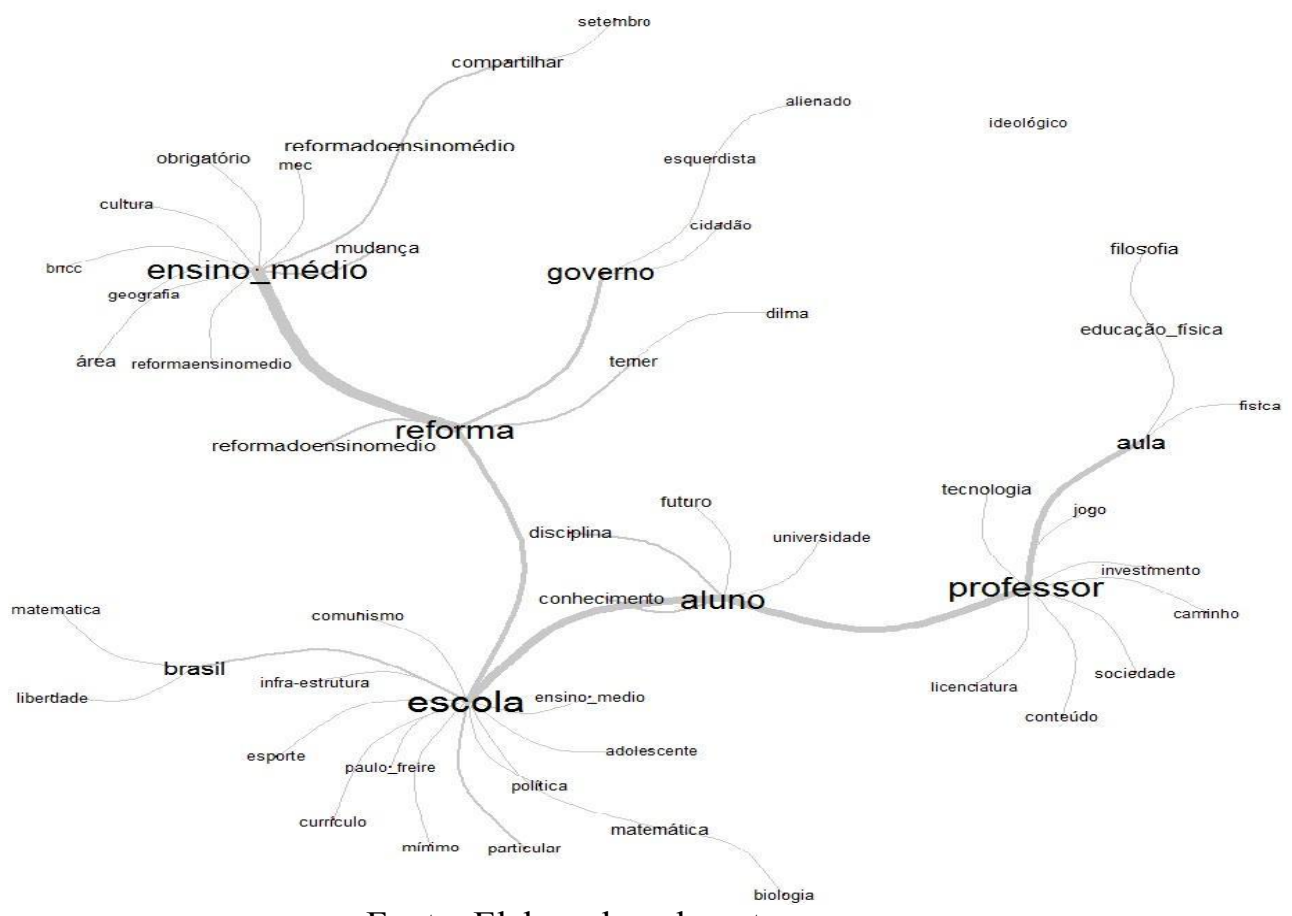

Fonte: Elaborado pelo autor. 
Tanto no grafo de similitude quanto na nuvem de palavras, os vocábulos ensino médio, reforma, Governo, escola, professor e aluno expressam e representam a questão central que envolve as mudanças nessa etapa de ensino. Ao empreender um movimento de análise dos grifos da direita para a esquerda, trazendo os elementos semânticos que circundam os vocábulos principais na Figura 3, podem-se averiguar os sentidos sociopolíticos que incidem sobre os desdobramentos dos rearranjos curriculares para as escolas de ensino médio. Por sua vez, eles terão de adequar-se infraestruturalmente à sua própria função social, no que diz respeito ao compartilhamento de conhecimentos para a figura do aluno, cujo sentido tem assentado principalmente no acesso ao ensino superior em suas disposições nos itinerários que, por sua vez, incidirão nas licenciaturas que formarão os futuros professores e, consequentemente, na atuação docente desse sujeito.

A Figura 4 é uma postagem no Instagram que sintetiza, de modo significativo, a polarização assumida sobre as questões políticas que envolvem a conjuntura brasileira, cujos desdobramentos estão expressos nas narrativas sobre a reforma curricular do ensino médio.

Figura 4 - Síntese de discursos de direita e esquerda expressos na reforma curricular do ensino médio
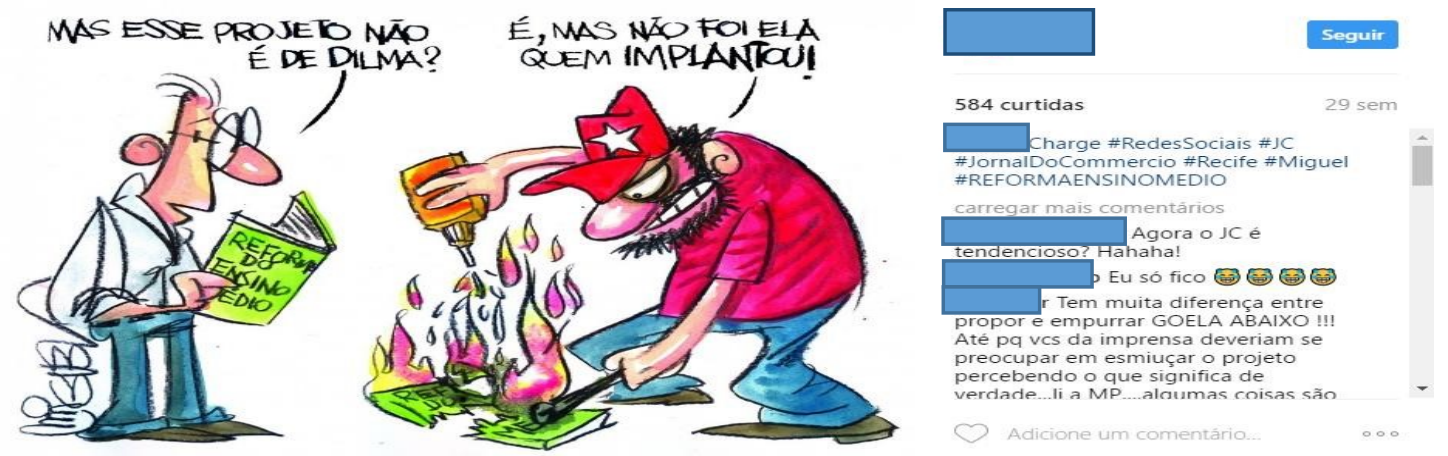

Fonte: Extraída de Instagram.

Instagranzeiro 1: Essa charge é mais uma prova de que político e partido nunca pensaram no povo nem no país, e sim em seus projetos pessoais e de poder. Não importa quem criou, o que importa é se vai modernizar ou não a educação. Sem falar que o projeto ainda vai passar por uma longa discussão com especialistas. Não tem nada decidido, apenas um pequeno grupo já querendo tumultuar. Porque inclusive uma grande parte dos educadores apoiam essa iniciativa. Digo INICIATIVA, ou seja, é apenas o início da discussão.

Nessa fase das discussões os tensionamentos argumentativos relacionavam-se, de um lado, à fragilidade que envolve a realização de uma reforma, como esta, por meio de medida provisória, e não como um projeto de lei, amplamente debatido. E do outro lado o principal contra-argumento concentrava-se na demora em agir em prol do Ensino Médio, pois, na ótica desse grupo, por muitos anos se discute sobre o "fracasso" do ensino médio e nada tem sido realizado, de maneira consistente, por essas mesmas entidades e grupos políticos que agora, criticam a reforma. 
Instagranzeiro 2: Tem muita diferença entre propor e empurrar GOELA ABAIXO! Até pq vcs da imprensa deveriam se preocupar em esmiuçar o projeto percebendo o que significa de verdade...li a MP... algumas coisas são interessantes, mas na maior parte da coisa parece um projeto amador...deveriam ter vergonha de divulgar uma coisa sem pé nem cabeça.

Diante da materialidade textual que as fontes sinalizavam e das pistas e indícios (GINZBURG, 2002) deixados nas Figuras 3, 4, e da ampliação da análise dos dados, iniciou-se o movimento de captura das narrativas evocadas sobre a Educação Física no contexto dessa reforma. Com isso, a fim de ampliar a compreensão sobre os sentidos das palavras de recorrência significativa, realizou-se mais um procedimento: a extração de fragmentos textuais produzidos nos comentários e discussões realizadas nas mídias sociais.

\section{Desdobramentos para a Educação Física no ensino médio}

As fontes se mostraram valiosas não somente para situar o debate e as ressonâncias dos impactos relacionados com a MP $\mathrm{n}^{\mathrm{o}}$ 746/2016, mas também para dar visibilidade às práticas $\mathrm{e}$ consumos que envolvem esse componente curricular nessa etapa de ensino médio, em que o ciberespaço se torna um lugar de vinculações, frustrações, críticas e expressões de afeto do que ocorre no contexto escolar

As postagens iniciais estavam associadas à possível retirada da obrigatoriedade da Educação Física e assumem caráter de reivindicação e protesto, inclusive de pesquisadores da área, como a seguinte postagem em 26 de outubro de 2016, ${ }^{6}$ na página da carta Educação no Facebook:

[...] como consequência da retirada da obrigatoriedade da Educação Física do currículo do Ensino Médio, prevista pela Medida Provisória da reforma do Ensino Médio, corremos o risco de vermos o aumento da discriminação em relação às práticas corporais e culturais contra hegemônicas. Muitos meninos e meninas ficarão impedidos de conhecer e de se reconhecer como sujeitos dessas culturas.

Argumentos também tecidos por um professor aposentado renomado da Educação Física, em sua página pessoal no Facebook:

Vamos lá: a Educação Física no Ensino Médio é ruim? De modo geral, é. A Matemática no Ensino Médio é ruim? De modo geral, é. A Física no Ensino Médio é ruim? De modo geral, é. Vamos acabar com tudo então? Claro que não. Temer deu golpe também no Ensino Médio.

\footnotetext{
${ }^{6}$ Vale, aqui, retomar o seguinte fato: o envio da MP n 746 ocorreu no dia 22 de setembro de 2016, porém as primeiras publicações científicas encontram-se no v. 29 de 2017, na revista Motrivivência, que organizou uma edição especial sobre as mudanças em curso. Em outras palavras, as mídias utilizadas por esses pesquisadores assumem um papel de destaque para o "fazer" circular das impressões iniciais sobre os desdobramentos dessa medida provisória.
} 
Palavras de indignação e revolta também foram escritas por sujeitos ordinários, que vivem o cotidiano da Educação Física no ensino médio de algum modo:

Facebookeiro 1: Precisamos reagir! Mudanças são positivas e devem ser feitas no Ensino Médio, mas fazer-nos engolir uma forma por meio de uma MP que impõe retiradas drásticas da Arte e da Educação Física e que permite que qualquer um possa dar aula por notório saber.

As análises provocam, inicialmente, uma interpretação de aparente desvalorização desse componente curricular nessa etapa de ensino. Porém, deve-se questionar se a própria escola, de modo geral, também está permeada de imprecisões e incompreensões quanto as suas finalidades no contexto histórico atual, cujas ressonâncias também alcançam a Educação Física, como pode ser exemplificado na postagem da figura 4:

Figura 4 - Postagem no Instagram de reafirmação da importância da Educação Física

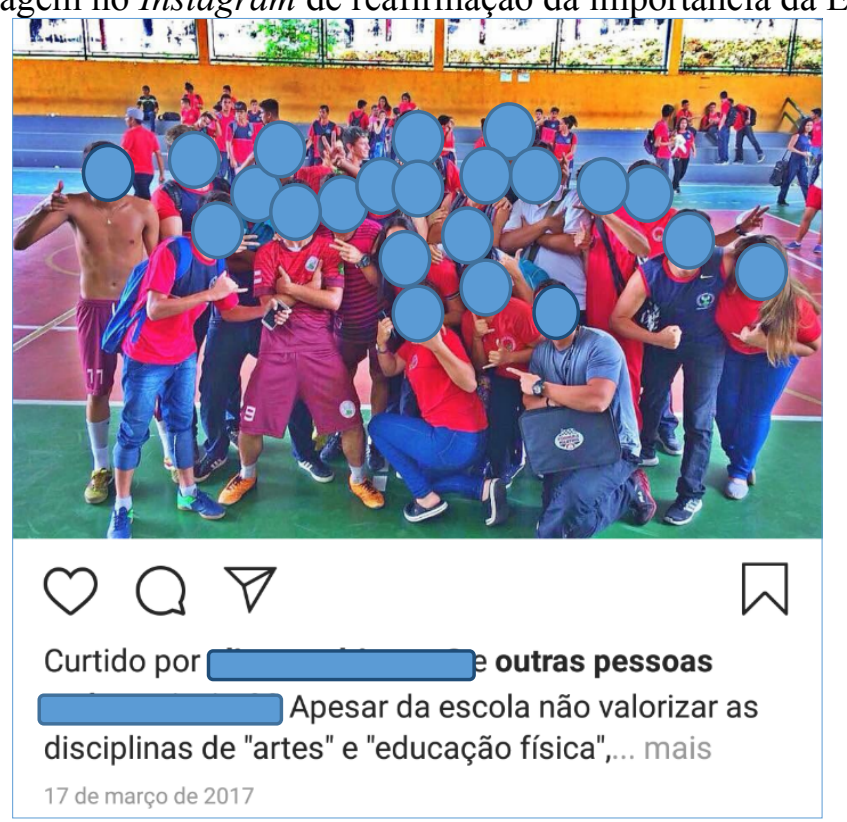

Fonte: Extraído de Instagram.

Ao longo da textualidade das narrativas transcritas, é possível destacar também a reafirmação de certas hierarquizações no que se refere a conhecimentos disciplinares tidos como mais importantes do que em relação a outros, para serem compartilhados no projeto de escolarização do ensino médio. Assim, as disciplinas Matemática, Português e Inglês são apresentadas como fundamentais e, por isso, devem ser obrigatórias durante os três anos.

Indícios podem sustentar esse pressuposto, por exemplo, quando ocorre a adequação do texto da medida provisória que não mais retirava a obrigatoriedade da Educação Física, mas sim de componentes como Filosofia e História. Ou seja, as narrativas evidenciam, nesse ponto, tensões, disputas e uma relativização do ponto de vista curricular. Devido à tradição de escolarização, não se pode aceitar a perda de nenhuma disciplina, mas, se é para retirar, façam com aquelas cujos saberes 
estão mais confusos ou dissonantes face ao tipo de saber difundido culturalmente como mais relevante e importante, por exemplo, para os postos superiores de trabalho e/ou para alcançar um resultado expressivo no Enem. Com isso, o acesso e conhecimento aos saberes das práticas corporais tornam-se secundários aos de outras áreas, se for para escolher entre uma e outra.

Twitteiro 1: Essa reforma do ensino médio não faz sentido! Educação Física deveria ser opcional, História e Geografia obrigatórios.

Twitteiro 2: Educação Física vai ser obrigatório no novo ensino médio e essa é a coisa mais inútil que eu já vi na vida.

Twiteiro 3: cólica menstrual, mosquito e Educação Física no ensino médio são as coisas mais inúteis que existem pra mim $k k k k$.

Sobre a hierarquização de saberes, tomando como exemplo a Educação Física, a partir de uma possível desvalorização dos saberes constituídos por essa área no contexto escolar, a instituição escolar constrói códigos e símbolos ancorados pela tradição, que colaboram na valorização de um saber e aprender em detrimento de outros. Dessa maneira, a escola assume modos de organização e operacionalização de aprendizagens universais que devem alcançar a todos da mesma forma e intensidade. Assim, disciplinas que assumem uma dimensão de práticas ocupam um lugar menos privilegiado, embora os alunos as compreendam positivamente, não com os mesmos sentidos que atribuem a outras disciplinas, e sim por sua estrutura, por possibilitar-lhes experiências de saber com as práticas corporais (SANTOS et al., 2016).

Schneider e Bueno (2005), Santos et al. (2014) e Santos et al. (2016) sinalizam outras pistas dessa condição, uma delas refere-se as experiências corporais desenvolvidas no contexto extraescolar que colaboram para que o entendimento sobre as aprendizagens específicas da Educação Física seja de difícil descrição para os alunos, pois eles não compreendem o que diferenciaria brincar, jogar e praticar esportes na rua, escolinhas daquilo que é aprendido nesse componente curricular no contexto escolar.

Tais elementos são expressos nos seguintes trechos:

Twiiteiro 4: A gente foge de Educação Física no ensino médio inteiro pra pagar academia aos 30 anos de idade.

Yotuber 1: Educação Física não ensina coisa nenhuma de equipe. Só serve pra alguns alunos quererem se mostrar e humilhar os outros que não são bons em esportes. Melhor vc msm fazer um esporte extra-escolar que vc goste e deixar uma declaração na escola. ai sim seria interessante...

Youtuber 2: Então, a matéria de Educação Física nas escolas sempre foi muito marginalizada desde sempre e apenas depois de 1996 que se tornou obrigatória para alguns niveis de ensino.

Essas hierarquizações incidem sobre as especificidades das práticas pedagógicas em Educação Física, principalmente na escolha e seleção dos conteúdos a serem compartilhados. Matos 
(2013) sinaliza que, do ponto de vista dos professores, dança, ginásticas, lutas, capoeira, jogos, brincadeiras e esportes têm sido os conteúdos mais relevantes a serem ensinados nas aulas de Educação Física, o que pode residir na aproximação entre escola e contexto cultural pertencido, aspectos que colaboram nas apropriações e usos dos docentes em suas aulas. Esses elementos podem ser confirmados a partir dos trechos:

Twitteiro 5: Chega no ensino médio Educação Física vira anatomia.

Twitteiro 6: Ainda bem que não tiraram Educação Física da grade do ensino médio, imagina se mais gente chega aos 20 anos sem saber pular corda.

Twitteiro 7: E eu que no ensino médio pensava que Educação Física era só jogar bola! Não aguento mais estudar.

Twitteiro 9: hoje minha turma brincou de pique pega na Educação Física kkkkkkkk nem parece que estamos no último ano do ensino médio.

Facebookeiro 4: Ginástica Circense $1^{\circ}$ ano do Ensino Médio atividades : Malabares, rolamento pra frente, rolamento pra trás, exercícios acrobáticas e atividades que trabalham a confiança com o próximo.

materiais utilizados: Bolinha reciclada (que vem no desodorante rolon) e Tatame e muita criatividade!

Facebookeiro 5: Treinamento Funcional na Educação Física Escolar - Ensino Médio Espera-se que os alunos ao iniciar o Ensino Médio sejam portadores de um rico acervo motor.

Evidencia-se, também, a associação entre Educação Física e esportes, uma vez que as fontes indicam a predominância de consumo desse conteúdo, com destaque ao ensino e aprendizagem das regras de modalidades tradicionais, cuja finalidade se ancora na competição olímpica. Os sujeitos consideram o esporte um conteúdo fundamental, todavia divergem quanto à seleção, oferta e compartilhamento, que, por sua vez, incidem sobre suas finalidades.

Youtuber 3: Educaçao fisica na escola se resume: jogar futebol... Nao se aprende mais nada... Não se aprende as regras de esportes olimpicos ,etc... Educaçao fisica é perda de tempo... A nao ser q faça essa reforma e obrigue professor a ensinar no minimo regras de todos os esportes olímpicos, ai sim seria uma boa e um incentivo pro povo.

Youtuber 6: E Educação Física por exemplo? Essa matéria sempre me segregou, sou muito ruim com esportes e minhas notas sempre foram horriveis nessa matéria, fora que, pra que eu preciso saber quantos jogadores têm em um time de basquete sendo q odeio esportes? E não venham falar q é pra manter minha saúde e não sei oque, porque eu sempre fico lá sentado nas aulas sem fazer nada, e se eu quisesse praticar esportes, eu entrava em um treino de futebol ou algo do gênero.

Kravchychyn e Oliveira (2012) indicam alguns elementos sobre o lugar do esporte nas representações dos alunos. Para os autores, isso se deve à ampla vinculação sociocultural do esporte presente em diferentes contextos e momentos do cotidiano das pessoas na mídia, nos assuntos do dia a dia ou mesmo para constituir-se como uma opção profissional. Assim, a Educação Física, como uma das áreas que colaboram na apresentação e ensino desse conteúdo, tem sido por vezes 
confundida com o próprio esporte. Concomitantemente a isso, tem-se, ainda, que as demais práticas corporais são esportivizadas, principalmente via movimento olímpico, e produzem um entendimento de aprendizagem associativa entre esporte e Educação Física.

Esses aspectos remetem às possíveis dificuldades de ensinar outros conteúdos para os alunos. Rosário e Darido (2005) entendem a insegurança dos professores em ministrar conteúdos que não dominam, principalmente do ponto de vista da experiência, ou seja, quanto menos familiar for a prática esportiva, mais resistência do professor em ensiná-la. Outro ponto levantado está no modo como o ano letivo está dividido, bimestral ou trimestralmente, condições que delimitam, de certa forma, o tempo do que deve ser ensinado. Os autores ressaltam, ainda, que, mesmo com o aumento da produção científica sobre outros conteúdos, é notório um distanciamento entre essas pesquisas e o chão da escola.

Entretanto, com base na leitura positiva (CHARLOT, 2000), pode-se evidenciar como o esporte, a partir dos usos e consumos estabelecidos entre os alunos com esse componente curricular, assume um lugar de destaque em relação às demais práticas corporais ofertadas, a ponto de associar a própria Educação Física ao ensino dos esportes. Isso sugere um movimentar-se da área em direção não à ruptura ou secundarização desse conteúdo, como realizado em outros momentos no campo, mas sim à possibilidade de maior valorização das outras práticas corporais, que são evocadas nas narrativas da trajetória de escolarização que os sujeitos ordinários estão percorrendo ou percorreram.

Esse modo de fazer produz ressonâncias sobre as práticas avaliativas. Nas transcrições, é possível perceber que a dificuldade de compreender os saberes compartilhados pela Educação Física tem incidência sobre o ato de avaliar, pois, se essa disciplina apresenta dificuldades de entendimento do seu lugar na representação dos saberes escolarizados, na percepção dos alunos, qual o sentido de ser avaliado? Diante disso, quando o professor se apropria de instrumentos, que valorizam o saber enunciado, utilizados por outras disciplinas associados à representação da atribuição de uma nota com valor numérico que condiciona o aluno a ser aprovado ou ser reprovado, a Educação Física incorre no equívoco de comparar-se com outras disciplinas do currículo, tornando ainda mais conflituosas as relações que envolvem o tipo de saber que essa disciplina compartilha:

Twitteiro 10: decadência no ensino médio é ter prova de Educação Física.

Twitteiro 12: EDUCAÇÃO FÍSICA NEM DEVIA CONTAR NO ENSINO MÉDIO COMO MATÉRIA DE BOLETIM.

Twitteiro 14: que tipo de pessoa no último ano do ensino médio tem prova de Educação Física mano era pra eu tá fazendo simulado. 
Twitteiro 15: Educação Física obrigatória no ensino médio, agora o Enem vai ser queimada na quadra.

Twitteiro 16: ainda não entendi o porque de no ensino médio existir prova teórica de Educação Física.

Para Santos et al. (2015), é preciso situar as práticas avaliativas em Educação Física em relação aos saberes escolarizados e pelas especificidades desse componente curricular, ou seja, a valorização dos saberes de domínio e relacional, nas experiências do fazer com as práticas corporais na dimensão dos saberes-objetos, deve orientar os processos avaliativos. Não significa dizer que os alunos não podem materializar de outras formas os aprendizados, como em provas escritas e outras produções; porém, nas transcrições, percebe-se que a representação dos modelos de avaliação de outras disciplinas dos saberes orais e escritos dificulta o entendimento das práticas avaliativas em Educação Física, quando se privilegiam esses instrumentos. Essa incompreensão pode estar associada ao modo como os alunos tem se relacionado com os saberes próprios da área da Educação Física e consequentemente também, com as práticas avaliativas selecionadas pelos professores ao longo do percurso de escolarização, em que para Santos, Maximiano e Fossard (2016) ainda tem prevalecido modos não sistematizados de avaliar, cujos critérios são comportamentais sobre assiduidade e participação nas aulas. Secundarizando as aprendizagens decorrentes das apropriações sobre os saberes próprios das aulas de educação física, com destaque as práticas corporais em suas nuances socioculturais.

São questões que evocam o tipo de formação que esse professor de Educação Física tem realizado. Betti, Ferraz e Dantas (2011), Vieira (2011) sinalizam a carência de estudos sobre a formação profissional em Educação Física na especificidade do ensino médio. O trabalho de Vieira, Santos e Ferreira Neto (2012), apesar de não tratar especificamente do ensino médio, deixa algumas pistas sobre os critérios utilizados para seleção e sobre determinados conteúdos e práticas. Os resultados das pesquisas indicam que as experiências sociocorporais realizadas ao longo da vida, não somente nas disciplinas da graduação, constituem-se como lugares de segurança na hora de ensinar a seus alunos determinados conteúdos. Assim, quanto menor a experiência com uma determinada prática corporal ou estratégia pedagógica, mais dificuldade em trazê-los para o cotidiano de suas aulas.

Por outro lado, as narrativas evidenciam algumas dissonâncias relacionadas com os modos como os alunos percebem os fazeres dos professores de Educação Física, destacando-se as frustrações pela oportunização não sistematizada e com baixa diversificação das práticas corporais. Confrontam também a postura ética do professor no desenvolvimento e organização de suas aulas. Dessa forma, trazem de modo implícito expectativas quanto ao que esperam da figura do professor, aspecto a ser considerado nas discussões sobre a formação e atuação profissional desse sujeito. Se, 
por um lado, não é coerente a denúncia fatalista e recorrente a esse profissional, por não se saber as condições de sua prática, faz-se também incoerente negligenciar as expectativas que os alunos possuem em relação ao perfil do que consideram um bom professor. Ademais, é significativo compreender as razões e os processos de constituição desse tipo de fazeres envoltos por esse sujeito.

Twitteiro 17: Minha professora de Educação Física no ensino médio jogava a bola no meio da quadra e depois ia sentar na sombra pra fumar...

Twiiteiro 18: Quando você teve certeza que era em ed fisica que você queria se formar? Quando eu tive aula de Educação Física bem ruim no ensino médio e queria fazer diferente.

Twitteiro 19: Educação Física serio isso na minha escola é só futebol e nada mais ainda o professor sai para toma café Ensino Médio.

Para Charlot (2013) o professor tem consciência de estar preso em discursos contraditórios, que se desdobram em uma perspectiva impessoal da atuação docente que, por sua vez, se transforma em vitimização, indignação e desmobilização. A contradição é parte do modo como se constitui o fazer docente.

É preciso também considerar as angústias e frustrações entre os professores provenientes do pouco interesse e distanciamento dos alunos no modo de se relacionar com o componente curricular Educação Física. Elementos que podem estar associados a possíveis incompreensões e tensionamento quanto ao lugar dessa área no contexto de escolarização. Que se associam ainda com a hierarquização dos saberes que a escola produz, valorizando os saberes da escrita e oralidade, em detrimento a saberes de domínio, como aqueles corporais (SCHNEIDER; BUENO, 2005).

Por fim, esses elementos colaboram para a construção das narrativas que indicam questões relacionadas com os sentidos e finalidades que a Educação Física assume no contexto escolar. Para Han (2018) essas estruturas provenientes das práticas discursivas no ciberespaço sugerem um comportamento do tipo enxame e cardume construído a partir de um imaginário tencionado por algoritmos que indicam modos representativos que aproximam grupos e pessoas, em perspectivas e eixos em comum, que por sua vez incidem sobre comportamentos, posições e argumentos sobre elementos específicos. Com isso, em um primeiro momento as pessoas se conectam por fragmentos representativos de temáticas consensuais, subsequentemente conforme as discussões e argumentos são enunciados há um processo de expansão, reorganização e direcionamentos uníssonos de aparentes verdades argumentativas, inflexíveis. O grupo assim produz barulho, forma um enxame, produzindo uma consonância de massa, com pouca ou nenhuma coerência, mas não desenvolve ação de massa, pela ausência de um nós. Performatizando-se em homos eletronicus, ou aquele ser conectado cuja identidade foi dissolvida psiquicamente e o homo digitalis, aquele individuo que 
mesmo em grupo mantem sua identidade e utiliza do virtual como espaço de reafirmação e de reafirmação de si mesmo e suas posições.

Desse modo, desenvolvem narrativas quase hegemônicas, que tencionam, por exemplo, ao entendimento de que a Educação Física é uma aula vaga, ou uma atividade, ou mesmo um momento para os alunos se distraírem e relaxarem das disciplinas de sala. Por outro lado, embora, de modo discreto emergem contranarrativas que apresentam pistas e indícios de perspectivas plurais de currículo, por exemplo, que contribuam para a atividade física e a saúde, bem como o lazer e a qualidade de vida dos estudantes.

Twitteiro 21: \#educacaofisica fora do ensino médio e a população q esta com sobrepeso futuramente será super obesa!

Twitteiro 22: Não acabem com a \#EducacaoFisica no ensino médio, os jovens precisam disso, entretenimento, qualidade de vida, trabalho em equipe!

Twitteiro 23: Tenho sdds da Educação Física da escola pq la era o único meio de fazer exercicios, agr q acabou o ensino médio estou oficialmente sedentária.

Twitteiro 24: eu acho educação física no ensino médio completamente inutil pq nao torna ngm fitness e so tira horário de aulas importantes.

Durante o percurso histórico da Educação Física no contexto escolar, ela foi passando por ressignificações das suas práticas e de suas finalidades, mantendo propósitos profiláticos, morais e culturais. Mesmo diante dessas diferentes (re) apropriações apresentadas ora como estratégia, ora como tema; ora como atividade, ora como componente curricular, ela tem ocupado um lugar na educação escolarizada brasileira, mesmo que, ao longo do tempo, conteúdos tenham sido modificados, ampliados ou excluídos, condição que faz com que sua(s) finalidade(s) ainda esteja(m) em aberto (BELTRAMI, 2001).

Essas questões são anunciadas, de modo polifônico no entre fluxo das narrativas, para além de posições individuais, grupais ou outros formatos interativos como o exemplo da revista Superinteressante, que em sua página no Facebook, publicou uma matéria com as seis lições que se aprende em Educação Física, que remetem, entre tantas questões, aos sentidos e finalidades do currículo em Educação Física. A seguir alguns dos exemplos apresentados:

Primeira lição: De pique-bandeira a beisebol, ser o último escolhido em todas as equipes, para todos os esportes, em qualquer posição (será que não dá para jogar com um a menos, fessor?) não foi ruim. Na realidade, nos ensinou a ser resilientes, a não procurar a aprovação dos outros e, sim, a encontrar validação em nós mesmos. Deve ser verdade, porque é o que a minha psicóloga me diz desde a $8^{a}$ série.[...] Terceira lição: Se existia um momento democrático da aula de Educação Física, era a queimada. Todo mundo tinha algo a contribuir: era o único esporte, afinal, em que fugir da bola era uma vantagem! A bolada na cara deixava de ser exclusividade dos menos favorecidos esportivamente. 
A constituição do campo currículo somada às pesquisas com/nos/dos cotidianos (SANTOS, 2016) permitem situar a compreensão dos cotidianos escolares da educação física conforme as diferentes tessituras provenientes dos lugares e os sujeitos de sua produção. Ou seja, é preciso lançar uma perspectiva sobre as questões das narrativas e representações enxames/cardumes (HAN, 2018), mas não se pode esvaziar as nuances próprias que envolvem as estratégias e táticas (CERTEAU, 2002) provenientes dos modos como os sujeitos praticam e tecem seus cotidianos em suas autorias pedagógicas.

Um dos elementos que têm sido utilizados para justificar o lugar da Educação Física no currículo do ensino médio está em sua obrigatoriedade estabelecida pelas políticas educacionais, mais especificamente na elaboração da LDB n. ${ }^{\circ}$ 9.304/1996, que, ao longo dos anos, tem sido alterada:

§ 3․ A Educação Física, integrada à proposta pedagógica da escola, é componente curricular obrigatório da educação básica, sendo sua prática facultativa ao aluno: (Redação dada pela Lei.$^{\circ}{ }^{\circ} 10.793$, de $1 .^{\circ} .12 .2003$ );

I - que cumpra jornada de trabalho igual ou superior a seis horas; (Incluído pela Lei n. ${ }^{\circ} 10.793$, de $\left.1 .^{\circ} .12 .2003\right)$;

II - maior de trinta anos de idade; (Incluído pela Lei ${ }^{\circ} 10.793$, de $1 .^{\circ} .12 .2003$ );

III - que estiver prestando serviço militar inicial ou que, em situação similar, estiver obrigado à prática da Educação Física; (Incluído pela Lei n. ${ }^{\circ}$ 10.793, de 1. $\left.{ }^{\circ} .12 .2003\right)$;

IV - amparado pelo Decreto-Lei n. ${ }^{\circ} 1.044$, de 21 de outubro de 1969; (Incluído pela Lei . $^{\circ} 10.793$, de $\left.1 .^{\circ} .12 .2003\right)_{2}$

$\mathrm{V}$ - (VETADO) (Incluído pela Lei n. ${ }^{\circ} 10.793$, de 1. ${ }^{\circ} .12 .2003$ );

VI - que tenha prole. (Incluído pela Lei n. ${ }^{\circ} 10.793$, de $1{ }^{\circ} .12 .2003$ ).

Se, por um lado, a LDB n. ${ }^{0}$ 9.394/1996 colabora para reafirmar a condição da Educação Física como componente curricular obrigatório, por outro possibilita interpretações quanto às suas especificidades, principalmente voltadas ao esforço físico, aspecto que justificaria a condição de disciplina facultativa aos grupos apresentados nos artigos da lei em questão.

Esses elementos podem ser averiguados no teor das transcrições:

Twiteiro 25: oq tem na cabeça de um professor de Educação Física pra querer obrigar alunos do ensino médio a fazer a aula????

Twitteiro 28: caso vcs se achem preguiçosos saibam que peguei recuperação em EDUCAÇÃO FÍSICA no segundo ano do ensino médio por simplesmente não ir pra aula.

\section{CONSIDERAÇÕES FINAIS}

Por fim, conforme as questões anunciadas por este estudo é possível concluir que a reforma do ensino médio tem sido temática recorrente nas discussões realizadas nas mídias sociais analisadas, inicialmente, com base na MP no 746 e seu envio ao Congresso. As principais 
discussões contra essa medida nessa primeira fase estavam relacionadas com a perda da obrigatoriedade dos componentes curriculares Educação Física, Artes, Sociologia, Filosofia e História.

É possível dizer que, entre as mídias sociais analisadas, o Youtube se constituiu como principal fonte analítica, condição que se justifica pela quantidade de produção textual bem como pelas possibilidades interativas que essa mídia possibilita. Isso pode ser consequência de sua interface, na qual um vídeo é produzido e os demais membros têm um espaço para comentar aquele assunto. Por outro lado, o Twitter foi a mídia social com maior organização de elementos textuais que argumentavam sobre o objeto deste estudo. Isso pode ser consequência da especificidade dessa fonte, que limita a 280 caracteres a postagem do usuário. Sendo possível averiguar que a construção de vários twits na sequência sobre um mesmo tema não são bem vistos pelos usuários dessa mídia.

Nos tensionsamentos narrativos que envolvem o lugar da Educação Física assumem caracteres significativos quando sua obrigatoriedade é posta em xeque no ensino médio com a reforma. Há perspectivas sustentadas por narrativas apresentadas pelos sujeitos do espaço online, que se organizam desde as frustações com conteúdos sobrepostos até a dificuldade de entendimento do lugar e do sentido das aprendizagens desse componente nessa etapa da escolarização. Por outro lado, aqueles que discordam dessa flexibilização o fazem com argumentos que se direcionam a importância do acesso plural aos diferentes saberes, inclusive de natureza corporal. Bem como os retrocessos provenientes do não acesso as práticas corporais com intuito de um ideário para a educação para a atividade física regular.

Por fim, tais reflexões somente são possíveis devido ao movimento de escuta das vozes que foram silenciadas diante de tal reforma, dos sujeitos do ensino médio, principalmente alunos e professores. Somente assim, é possível perceber as nuanças que cercam o cotidiano do ensino médio e da Educação Física. Aspectos que colaboram no processo de averiguar os dilemas, as tensões e os indícios de um projeto de escolarização que está a ser configurado.

\section{REFERÊNCIAS}

AMARAL, Adriana; NATAL, Geórgia; VIANA, Luciana. Netnografia como aporte metodológico da pesquisa em comunicação digital. Revista Sessões do Imaginário, Porto Alegre, n. 20, p. 34-40, dez. 2008.

BELTRAMI, Dalva Marim. Dos fins da Educação Física escolar. Revista da Educação

Física/UEM, Maringá, v. 12, n. 2, p. 27-33, 2. sem. 2001. 
BETTI, Mauro; FERRAZ, Osvaldo Luiz; DANTAS, Luiz Eduardo Pinto Basto Tourinho. Educação física escolar: estado da arte e direções futuras. Revista Brasileira de Educação Física e Esporte, São Paulo, v. 25, n. Esp., p.105-15, dez. 2011.

BRASIL. Lei de Diretrizes e Bases da Educação Nacional. Lei número 9394, 20 de dezembro de 1996.

BRASIL. Ministério da Educação. Base Nacional Comum Curricular. Terceira Versão. Brasília: MEC, 2017.

CERTEAU, Michel de. A invenção do cotidiano: 1. artes do fazer. 15. ed. Petrópolis: Vozes, 2002.

CHARLOT, Bernard. Da relação com o saber: elementos para uma teoria. Porto Alegre: Artmed Editora, 2013.

GINZBURG, Carlo. Mitos, emblemas e sinais: morfologia e história. São Paulo: Companhia das Letras, 2002.

HAN, Byung-Chul. No enxame: perspectivas do digital. Petrópolis: Editora Vozes, 2018.

KOZINETS, Robert. Netnografia: a arma secreta dos profissionais de Marketing. 2010.

Disponível em: http://kozinets.net/wp-content/uploads/2010/11/netnografia_portugues.pdf. Acesso em: 15 nov. 2018.

KOZINETS, Robert. Netnografia: realizando pesquisa etnográfica online. Porto Alegre: Penso, 2014.

KRAVCHYCHYN, Claudio; OLIVEIRA, Amauri Aparecido Bássoli. Educação Física escolar e esporte: uma vinculação (im) prescindível. Revista Mackenzie de Educação Física e Esporte, São Paulo, v. 11, n. 1, p. 61-70, 2012.

LEVY, Pierre. Cibercultura. São Paulo: Ed. 34, 1999.

MATOS, Juliana Martins Cassani. Conteúdos de ensino da educação física escolar: da produção acadêmica às narrativas docentes. Dissertação (Mestrado em Educação Física). Programa de PósGraduação em Educação Física, Universidade Federal do Espírito Santo, Vitória, 2013.

MONTARDO, Sandra Portella; ROCHA, Paula Jung. Cartografia da utilização da mídia no espaço virtual em Novo Hamburgo: proposta de referencial teórico. Revista Gestão e Desenvolvimento, Novo Hamburgo, v. 2, n. 1, p. 63-67, jan./jun. 2005.

NOVELI, Marcio. Do off-line para o online: a netnografia como um método de pesquisa ou o que pode acontecer quando tentamos levar a etnografia para a Internet? Organizações em Contexto, São Paulo, v.6, n.12, p. 107-133, jul./dez. 2010.

Redação. O que é Hashtag. Disponível em: www.canaltech.com.br/produtos/o-que-e-hashtag/. Acesso em: 10 de janeiro de 2018.

POISSANT, Louise. A passagem do material para a interface. In: DOMINGUES, D. (Org.). Arte, ciência e tecnologia: passado, presente e desafios. São Paulo: Editora Unesp, 2009. p.71-90. 
RIBEIRO, Carolina. Conheça as redes sociais mais usada no Brasil e no mundo em 2018. Disponível em: www.techtudo.com.br. Acesso em: 10 de Junho de 2019.

ROSÁRIO, Luís Fernando Rocha; DARIDO, Suraya Cristina. A sistematização dos conteúdos da Educação Física na escola: a perspectiva dos professores experientes. Motriz, Rio Claro, v. 11, n. 3, p. 167-178, set./dez. 2005.

SANTOS, Wagner. dos. Constituição do campo do currículo e as pesquisas nos/dos/com os cotidianos. Movimento, Porto Alegre, v. 25, n.1, p. 107-126, jan./jun. 2016.

SANTOS, Wagner dos; MAXIMIANO, Francine de Lima; FROSSARD, Matheus Lima. Narrativas docentes sobre avaliação do ensino-aprendizagem: da formação inicial ao contexto de atuação profissional. Movimento, Porto Alegre, v. 22, n. 3, p. 739-52, jul./set. 2016.

SANTOS, Wagner. dos et al. O. Avaliação na Educação Física escolar: construindo possibilidades para a atuação profissional. Educação em Revista, Belo Horizonte, v. 30, n. 4. p. 153-179, out./dez. 2014.

SANTOS, Wagner. dos et al. O. Avaliação na Educação Física escolar: reconhecendo a especificidade de um componente curricular. Movimento, Porto Alegre, v. 21, n. 1, p. 205-218, jan./mar. 2015.

SANTOS, Wagner dos et al. A relação dos alunos com os saberes nas aulas de Educação Física. Journal of Physical Education, Maringá, v. 27, p. 27-37, 2016.

SCHINEIDER, Omar; BUENO, José Geraldo Silveira. A relação dos alunos com os saberes compartilhados nas aulas de Educação Física. Movimento, Porto Alegre, v.11, n. 1, p. 23-46, jan./abr. 2005.

VIEIRA, Aline Oliveira; SANTOS, Wagner dos; FERREIRA NETO, Amarílio. Tempos de escola: narrativas da formação discente ao ofício docente. Movimento, Porto Alegre, v. 18, n. 3, p. 119139, jul./set. 2012.

\section{NOTAS DE AUTOR}

\section{AGRADECIMENTOS}

Inserir os agradecimentos a pessoas que contribuíram com a realização do manuscrito.

\section{CONTRIBUIÇÃO DE AUTORIA}

Não se aplica.

\section{FINANCIAMENTO}

Não se aplica.

\section{CONSENTIMENTO DE USO DE IMAGEM}

Não se aplica. 


\section{CONFLITO DE INTERESSES}

Não se aplica.

\section{LICENÇA DE USO}

Os autores cedem à Motrivivência - ISSN 2175-8042 os direitos exclusivos de primeira publicação, com o trabalho simultaneamente licenciado sob a Licença Creative Commons Attribution Non-Comercial ShareAlike (CC BY-NC SA) 4.0 International. Esta licença permite que terceiros remixem, adaptem e criem a partir do trabalho publicado, desde que para fins não comerciais, atribuindo o devido crédito de autoria e publicação inicial neste periódico desde que adotem a mesma licença, compartilhar igual. Os autores têm autorização para assumir contratos adicionais separadamente, para distribuição não exclusiva da versão do trabalho publicada neste periódico (ex.: publicar em repositório institucional, em site pessoal, publicar uma tradução, ou como capítulo de livro), com reconhecimento de autoria e publicação inicial neste periódico, desde que para fins não comerciais e compartilhar com a mesma licença.

\section{PUBLISHER}

Universidade Federal de Santa Catarina. Programa de Pós-Graduação em Educação Física. LaboMídia - Laboratório e Observatório da Mídia Esportiva. Publicado no Portal de Periódicos UFSC. As ideias expressadas neste artigo são de responsabilidade de seus autores, não representando, necessariamente, a opinião dos editores ou da universidade.

\section{EDITORES}

Mauricio Roberto da Silva, Giovani De Lorenzi Pires, Rogério Santos Pereira

\section{HISTÓRICO}

Recebido em: 30 de setembro de 2019.

Aprovado em: 27 de fevereiro de 2020. 